\title{
FINDIĞIN POLİFENOLİK MADDELERİNİN ADSORBAN ÖZELLİKTE KOLON DOLGU MADDESİ KULLANILARAK FRAKSIYYONLARINA AYRILMASI VE ELDE EDİLEN FRAKSİYONLARIN KARAKTERİZASYONU
}

\author{
Ebru Pelvan* \\ TÜBİTAK Marmara Araştırma Merkezi, P.K. 21, 41470 Gebze, Kocaeli, Türkiye
}

Geliş / Received: 23.12.2019; Kabul / Accepted: 22.05.2020; Online bask1 / Published online: 22.06.2020

Pelvan, E. (2020). Fındığın polifenolik maddelerinin adsorban özellikte kolon dolgu maddesi kullanılarak fraksiyonlarına ayrilması ve elde edilen fraksiyonların karakterizasyonu. GID $A$ (2020) 45(4) 613-622 doi: 10.15237/gida.GD20011

Pelvan, E. (2020). Fractionation of hazelnutpolyphenolic compounds by using adsorbent featured column packing material and characterization of obtained fractions. GID A (2020) 45(4) 613-622 doi: 10.15237/gida.GD20011

\section{ÖZ}

$\mathrm{Bu}$ çalışmanın amacı, findığın içerdiği polifenolik maddelerin fraksiyonlarKına ayrılması ve elde edilen fraksiyonların karakterizasyonlarının gerçekleştirilmesidir. Bu amaçla, findığın fenolik maddeleri $\% 80(\mathrm{v} / \mathrm{v})$ asetonla ekstrakte edilerek kolona verilmiştir. Düşük molekül ağırlıklı (LMW) polifenolik maddeler etanol, yüksek molekül ağırlıklı (HMW) polifenolik maddeler ise aseton kullanılarak fraksiyonlanmışıı. Ayrıca LMW fraksiyonu, UV'de (280 nm'de) verdiği pik noktalarına göre dört ayın fraksiyona ayrılmışırı. Sonuçlar değerlendirildiğinde, tüm analizlerde en yüksek değerlere sahip olan Fraksiyon V'in toplam fenolik madde ve kondense tanen miktarları sırasıyla, $77.9 \mathrm{mg}$ gallik asit eşdeğer (GAE)/g ekstre ve $227 \mathrm{mg}$ kateşin eşdeğer (KE)/ g ekstre; antioksidan kapasite değerleri DPPH, ABTS ve FRAP yöntemleri için sirasıly $0.047 \mathrm{mg} / \mathrm{mL}$ IC $_{50}$ değeri, 1.442 mmol Troloks Eşdeğer (TE)/g ekstre, $307 \mathrm{mg} \mathrm{FeSO} \mathrm{H}_{4} .7 \mathrm{H}_{2} \mathrm{O} / \mathrm{g}$ ekstre olarak tespit edilmiştir. Çalışma sonucunda, LMW fraksiyonlarının ayrı fraksiyonlar olarak toplanmasına gerek olmadığı, HMW fraksiyonundan ayrılmasının yeterli olduğu tespit edilmiştir. HMW fraksiyonu, yüksek tanen içeriğiyle polifenolik maddeler açısından önemli bir kaynak olarak değerlendirilebilir.

Anahtar kelimeler: Antioksidan kapasite, findık, fraksiyonlama, kondense tanenler, toplam fenolik madde

\section{FRACTIONATION OF HAZELNUT POLYPHENOLIC COMPOUNDS BY USING ADSORBENT FEATURED COLUMN PACKING MATERIAL AND CHARACTERIZATION OF OBTAINED FRACTIONS}

\begin{abstract}
The aim of this study is fractionation of hazelnut polyphenols and their characterization. For this aim, phenolic compounds were extracted with $80 \%$ (v/v) acetone and loaded to column. Low molecular weight (LMW) and high molecular weight fractions (HMW) were fractionated with ethanol and acetone, respectively. Furthermore, LMW fraction was fractionated into four parts according to peaks observed at UV (280nm). FractionV had the highest contents/activities; total phenolics and condensed tannins contents were $77.9 \mathrm{mg}$ gallic acid equivalent (GAE)/g extract and $227 \mathrm{mg}$ catechin equivalent (CE)/ g extract, respectively. Antioxidant activities of FractionV were $0.047 \mathrm{mg} / \mathrm{mL} \mathrm{IC} 50$ value, $1.442 \mathrm{mmol}$ Trolox equivalent (TE)/g extract, $307 \mathrm{mg} \mathrm{FeSO} 4.7 \mathrm{H}_{2} \mathrm{O} / \mathrm{g}$ extract for DPPH, ABTS and FRAP assays, respectively. As a result, it is seen that further fractionation of LMW is not needed and separation of LMW from HMW fraction is enough. HMW fraction could be utilized as a potential source of polyphenols.
\end{abstract}

Keywords: Antioxidant activity, hazelnut, fractionation, condensed tannins, total phenolics content

\footnotetext{
* Yazışmalardan sorumlu yazar /Corresponding author

$\triangle$ ebru.pelvan@tubitak.gov.tr

(c) (+90) 2626773262

圆 (+90) 2626412309

Ebru Pelvan; ORCID no: 0000-0002-3479-9514
} 


\section{GİRİ̧̧}

Günümüzde beslenme modeli ile sağlık arasındaki yakın ilişki çeşitli bilimsel verilerle ortaya konmuş, yapılan çalışmalarla yaşam süresinin uzatılmasının yan1 sıra sağlıklı yaşam ve yaşam kalitesinin yükseltilmesi hedeflenmiştir. Tüm dünyada sağlıklı gıda, fonksiyonel gıda, nütrasötikler (destekleyici besinler), medikal gida, zenginleştirilmiş g1da, diyet gida ve benzeri pek çok kavram gündeme gelmiş ve sağlığ koruyucu ve iyileştirici olarak nitelendirilen bu gidaların üretimine hız verilmiştir (Alaşalvar ve Pelvan, 2009). Bu kapsamda, tamamen doğal besinlerden elde edilen biyoaktif özellikteki maddelerin günlük yaşamda tükettiğimiz gidalara eklenmesi ile ortaya çıkan ve sentetik özellik taşımayan fonksiyonel gidalar pazarı hızla büyümektedir.

Fonksiyonel gidalar pazarında piyasaya sürülen ürünlerin ve hammaddelerin çeşitliliği de her geçen gün artmaktadır. Yapılan bilimsel çalışmalar sonucunda sağllğa yararlı bitkilerin etken maddelerinin saflaştırılmasıyla gıda, ilaç ve kozmetik sanayinde kullanımı yaygınlaşmıştır. Bitkilerde ikincil metabolitler olarak adlandırilan ve biyolojik aktivite gösteren bu fenolik maddeler pek çok farklı gruptan oluşmaktadır (Gini ve Jothi, 2018; Milevskaya vd., 2019). Fenolik maddelerin gösterdikleri kimyasal özelliklere göre ekstraksiyon ve saflaştırma işlemleri farklilık göstermektedir.

Findık, flavan-3-ol, benzoik asit, flavonoller gibi fenolik maddeler açısından zengin bir kaynaktır (Taş ve Gökmen 2015; Ghirardello vd., 2016; Yuan vd., 2018; Lainas vd., 2016; Pelvan Pelitli vd., 2017; Armada vd., 2019; Taş vd., 2019). Fındığın bileşimindeki yă̆, protein, karbonhidrat, diyet lif, vitaminler (vitamin E), mineraller, fitosteroller (özellikle $\beta$-sitosterol) ve antioksidan Özellikteki fenolik maddelerin beslenme ve sağlıklı yaşam üzerinde önemli bir role sahip olduğu vurgulanmıştır (Yuan vd., 2018, Napolitano vd., 2018).

Kabuklu yemişlerin U.S. Food and Drug Administration (FDA- Gıda ve İlaç Dairesi) tarafindan kalp-dostu sağlıklı gidalar olarak tanımlanmasının ardından kabuklu yemişlerin karakterizasyonu, sağllk üzerine etkilerinin araştırılması kapsamındaki çalışmalar hız kazanmıştır (Alasalvar ve Bolling, 2015). Avrupa ve diğer batı ülkeleri değerlendirildiğinde findık (Corylus avellana L.), kabuklu yemişler içerisinde en popüler beşinci kabuklu yemiştir (INC, 2019). Türkiye ylllk 287.500 ton üretimi ile toplam üretimin \%63'ünü karş1lamakta ve dünyada en büyük üretici konumundadır (INC, 2019). Türkiye'de 18 çeşit findık yetiştirilmekte olup kalitelerine göre Giresun ve Levant olarak ayrilmaktadırlar. Tombul findık bu türler arasinda Giresun kalite olarak sınıflandırılmakta ve Türkiye findık üretiminin \%25-30'ini oluşturmaktadır (Pelvan vd., 2012; Taş ve Gökmen, 2015).

Fındık yan ürünlerinden (zarı, yeşil kabuğu gibi) elde edilen fraksiyonların antioksidan kapasiteleri ile ilgili yayınlar olmasına rağmen (Alasalvar vd., 2006; Shahidi vd., 2007; Barreira vd., 2008; Alasalvar vd., 2009; Pelvan vd., 2012) findıktan elde edilen fraksiyonlar ile ilgili çalışma sayısı yok denecek kadar azdır. Findıktan elde edilen ekstreler ve bunların fraksiyonlarının nutrasötik, gıda takviyesi, ilaç ve kozmetik sektöründe kullanma potansiyeli oldukça yüksektir. $\mathrm{Bu}$ sebeple, bu çalışmanın amacı findığın bileşimindeki polifenolik maddelerin adsorban kolon dolgu maddesi kullanılarak ayrilmasi ve elde edilen fraksiyonların karakterizasyonudur.

\section{MATERYAL VE YÖNTEM}

\section{Materyal}

Birinci kalite Türk Tombul findığ (Corylus avellana L.) Giresun'daki Fındık Araştırma Enstitüsü’nden temin edilmiştir. Güneş altında kurutulan (3 gün boyunca $\sim 20-25 \quad{ }^{\circ} \mathrm{C}$ 'de) kabuklu findiklar kontrollü kabinlerde $\left(5{ }^{\circ} \mathrm{C}\right.$ sicaklik ve $\% 65-70$ bağıl nemde) saklanmıştır. Analiz öncesi sert kabukları kırılan findıklar zarları ile birlikte analiz edilmiştir. Tüm kimyasalllar Sigma-Aldrich (Poznan, PL)'den temin edilmiştir.

\section{Yağı alınmış örneklerin hazırlanması}

Fındıkların yağını alma işlemi Pelvan Pelitli vd. (2017)'nin belirttiği yöntemde küçük değişikliklerle gerçekleştirilmiştir. Özetle, findıklar kahve değirmeninde (Bosch, Ljubljana, Slovenya) 3 dakika boyunca ögütülmüss ve sonrasinda 
Soxhlet düzeneğinde hegzan ile yağ1 uzaklaştırılmıştır (katı:sıvı oranı 1:10, w/v, 3 kez 15 dakikalık işlem, $\left.65^{\circ} \mathrm{C}\right)$.

\section{Ham ekstrelerin hazırlanması}

Yağ1 alınmış findık örneğindeki fenolik maddeler, kat1: sıv1 oran1 1:10 (w/v) olacak şekilde 80:20 (v/v) aseton/su karışımı kullanılarak ekstrakte edilmiştir. Bu işlem için çalkalamalı su banyosu (Julabo SW 22, Seelbach, Almanya) $70{ }^{\circ} \mathrm{C}$ 'de 15 dakika boyunca kullanılmıştır. Ekstrakte edilen kısım soğuduktan sonra dikkatli bir şekilde süzülmüş ve aynı işlem iki kez daha tekrarlanmıştır. Ekstraksiyon işlemi sonrası toplanan siv1 kısımdaki çözgen döner buharlaştırıcıda (model Büchi Rotavapor R-200, Büchi Labortechnik AG, Flawil, İsviçre) vakum altında $40{ }^{\circ} \mathrm{C}$ 'de uçurulmuştur. Kalan sulu kısım ise dondurmalı kurutucu (Freezone 6, 77530, Labconco Co., Kansas City, MO, ABD) kullanilarak (72 saat boyunca $-48{ }^{\circ} \mathrm{C}$ ve 0.046 mbar'dan başlayarak) kurutulmuştur. Elde edilen toz ham ekstre analiz edilene kadar $-20{ }^{\circ} \mathrm{C}$ 'de saklanmıştur.

\section{Fenolik fraksiyonların hazırlanması}

Toz ham ekstreyi fraksiyonlarına ayırmak için Pelvan Pelitli vd. (2017)'nin belirttiği yöntem küçük değişikliklerle kullanılmıştır. Özetle, \%95 etanolde (v/v) çözünen ham ekstre Sephadex LH20 gel ile doldurulmuş $(5 \times 40 \mathrm{~cm})$ ve $\% 95$ lik etanol geçirilmiş kolona dikkatlice verilmiştir. Düşük molekül ağırlıklı fenolik bileşenleri uzaklaştırmak için $1 \mathrm{~L}$ etanol akışı verilmiştir. Elde edilen elüsyonlar fraksiyon toplayıcıda (RediFrac, Pharmacia Biotech AB, Uppsala, İsveç) $4 \mathrm{~mL}$ hacimlerde ayrı tüplere toplanmıştır. Her bir tüpün absorbansı 280 nm'de ölçülmüştür. Elde edilen absorbans değerlerine göre tüpler dört farklı fraksiyon olacak şekilde bir araya getirilmiştir. Sonrasında kolonda kalan yüksek molekül ağırlıklı fenolik bileşenleri (tanen fraksiyonu) uzaklaştırmak için $600 \mathrm{~mL} \% 50$ aseton (v/v) akışı verilmiştir. Elde edilen toplamda 5 fraksiyon, döner buharlaştırıcıda (model Büchi Rotavapor R-200, Büchi Labortechnik AG, Flawil, İsviçre) vakum altında $40{ }^{\circ} \mathrm{C}$ 'de çözgenlerinden uzaklaştırılmıştır.
Toplam fenolik madde miktarının belirlenmesi

Fraksiyonların toplam fenolik madde miktarları, Folin-Ciocalteu yöntemi kullanılarak Pelvan vd. (2012)'nin belirttiği üzere analiz edilmiştir. Fraksiyonlar metanolde çözülmüş ve sonuçlar mg gallik asit eşdeğer (GAE)/g ekstre olarak verilmişsir.

\section{Kondense tanen miktarının belirlenmesi}

Fraksiyonların kondense tanen miktarları, vanillin metodunun modifiye hali kullanılarak Price vd. (1978)'nin belirttiği üzere analiz edilmiştir. Fraksiyonlar metanolde çözülmüş ve sonuçlar mg kateşin eşdeğer $(\mathrm{KE}) / \mathrm{g}$ ekstre olarak verilmiştir.

\section{Antioksidan kapasitelerinin belirlenmesi} DPPH (2,2-difenil-1-pikrilhidrazil) radikal süpürme kapasitesi

Fraksiyonlarin antioksidan kapasiteleri, DPPH radikali kullanılarak Amarowicz vd. (2009)'nin belirttiği üzere analiz edilmiştir. Fraksiyonlar metanolde çözülmüş ve sonuçlar başlangıçtaki DPPH radikalinin \%50'sini inaktive etmek için mL'de olmas1 gereken ekstre miktar1 olan IC $_{50}$ değeri olarak verilmiştir.

ABTS (2,2'-azino-bis-(3-ethylbenzthiazoline6-sulfonik asit) radikal süpürme kapasitesi

Fraksiyonlarin antioksidan kapasiteleri, ABTS radikali kullanılarak Koroleva vd. (2014)'nin belirttiği üzere analiz edilmiştir. Fraksiyonlar metanolde çözülmüş ve sonuçlar Trolox eşdeğer (TE)/g ekstre olarak verilmiştir.

\section{FRAP (Demir iyon indirgeyici antioksidan kapasitesi)}

Fraksiyonların antioksidan kapasiteleri, FRAP yöntemi kullanılarak Benzie ve Strain (1999)'nin belirttiği üzere analiz edilmiştir. Fraksiyonlar metanolde çözülmüş ve sonuçlar $\mathrm{mg}$ $\mathrm{FeSO}_{4} .7 \mathrm{H}_{2} \mathrm{O} / \mathrm{g}$ ekstre olarak verilmiştir.

İstatistiksel analiz. Tüm analizler üç paralel olacak şekilde çalışılmış olup sonuçlar üç paralelin ortalamas1 \pm standart sapma olarak verilmiştir. Şekil olarak verilen sonuçlarda standart sapma bar özelliği kullanılarak verilmiştir. Örnekler arasında istatistiksel açıdan farklılık olup olmadığının 
tespiti SPSS 22 versiyon (SPSS Inc., Chicago, IL, USA) kullanılarak analiz edilmiştir. Farklılıkların tespiti için ANOVA ve Student's t-test kullanılmıştır.

\section{SONUÇ VE TARTIŞMA}

Ham ekstrelerin hazırlanması ve fenolik fraksiyonların ayrilmasi

Fındıktan ham ekstrenin elde edilmesi için \%80 aseton/su (v/v) çözeltisi kullanılmıştır. Literatürde de belirtildiği üzere findıktaki toplam fenolik madde miktarının \%60-65'ini oluşturan kondense tanenleri (Contini vd., 2008) ekstrakte etmekte en etkin çözelti olan \%80 aseton/su çözeltisi hem yüksek molekül ağırlıklı hem de düşük molekül ağırlıklı fenolik maddelerin ekstraksiyonunda kullanılmaktadır [findık yeşil kabuğundan ekstraksiyon (Alasalvar vd., 2006); kabuklu yemişlerden ekstraksiyon (Karamać vd., 2007); diğer bitkilerden toplam fenolik madde ekstraksiyonu (Naczk ve Shahidi, 2004; Alasalvar vd., 2009; Monagas vd., 2009)]. Elde edilen ekstrenin verimi $4.27 \mathrm{~g} / 100 \mathrm{~g}$ findık olarak hesaplanmıştır. Karamać vd. (2007)'nin \%80 aseton kullanarak yaptıkları çalışmada ham ekstre verimini $8.48 \mathrm{~g} / 100 \mathrm{~g}$ findık, Pelvan Pelitli vd. (2017) ise $5.15 \mathrm{~g} / 100 \mathrm{~g}$ findık olarak belirtmiş̧ir.
Shahidi vd. (2007)'nin \%80 etanol kullanarak yaptıkları çalışmada ham ekstre verimini $2.26 \mathrm{~g} / 100 \mathrm{~g}$ findık olarak vermiştir. Çalışmalar arasındaki farklılıkların sebebi kullanılan findığın cinsi, hasat yılındaki iklim koşulları ve kullanılan çözgenin farklı olması olabilir.

Elde edilen ham ekstrenin Sephadex LH-20 gel ile doldurulmuş kolona $(5 \times 40 \mathrm{~cm})$ uygulanmasiyla elde edilen etanol elüsyonlarından toplanan 4 mL'lik hacimdeki her tüpün 280 nm'deki absorbans değeri okunmuştur. Elde edilen absorbans değerlerinden oluşturulan grafik yardımıyla ayrı tepe (pik) oluşturan her tüp grubu ayrı bir fraksiyon olarak toplanmıștır. Şekil 1'den görüleceği üzere toplamda dört (4) farklı fraksiyon elde edilmiştir. Etanol elüsyonu sonrası kolonda kalan yüksek molekül ağırlıklı fenolik bileşenleri (tanen fraksiyonu) uzaklaştırmak için kolona verilen aseton elüsyonu ise ayr1 bir fraksiyon olarak toplanmıştır. Kolon kromatografi yöntemi kullanılarak yapılan bu çalışmada toplamda beş (5) fraksiyon elde edilmiş olup verimleri Çizelge 1'de verilmektedir. En düşük verim $0.62 \mathrm{~g} / 100 \mathrm{~g}$ findık ile Fraksiyon I'de elde edilirken en yüksek verim ise $1.97 \mathrm{~g} / 100 \mathrm{~g}$ findık ile Fraksiyon V'te elde edilmiştir.

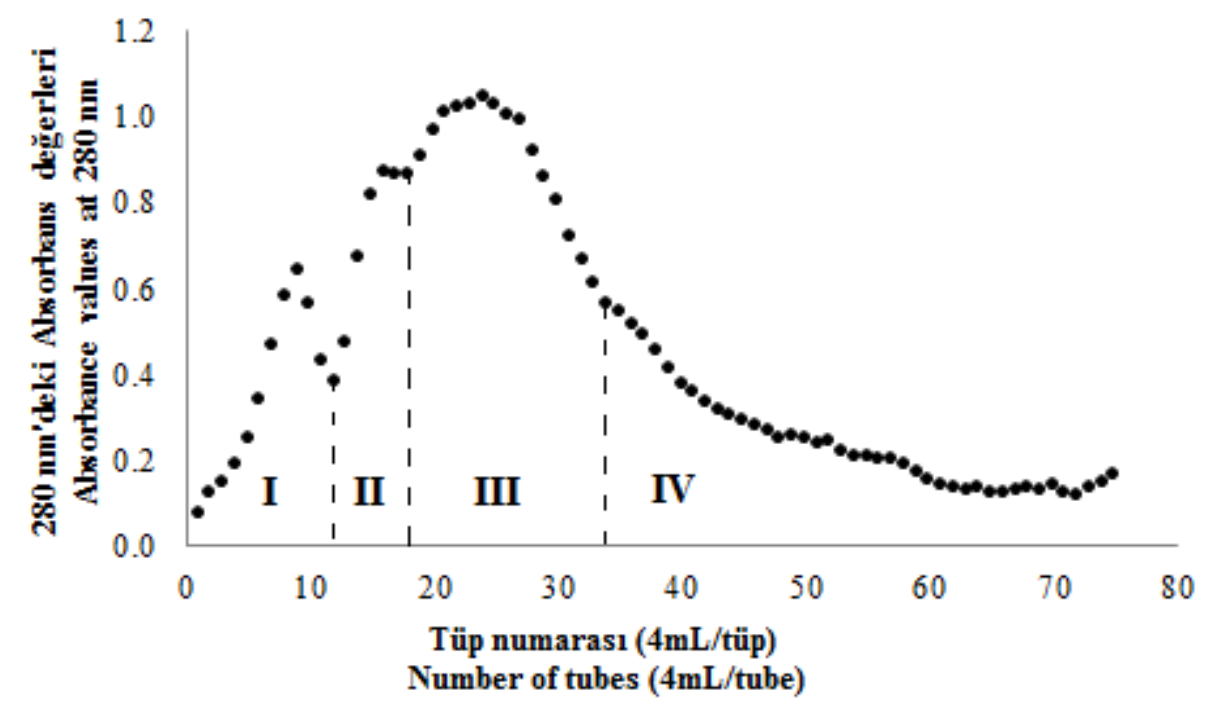

Şekil 1. Sephadex LH-20 dolgulu kolondan elde edilen etanol elüsyonlarının 280 nm'deki absorbans değerleri

Figure 1. Absorbance values of ethanolic elutions observed from Sephadex LH-20 packed column at $280 \mathrm{~nm}$ 
Çizelge 1. Elde edilen fraksiyonların verimleri, toplam fenolik madde ve kondense tanen miktarları Table 1. Contents of yield, total phenolics, and condensed tannins in fractions

\begin{tabular}{lccc}
\hline $\begin{array}{l}\text { Fraksiyon } \\
\text { Fraction }\end{array}$ & $\begin{array}{c}\text { Verim } \\
(\mathrm{g} / 100 \mathrm{~g} \text { findik }) \\
\text { Yield } \\
(\mathrm{g} / 100 \mathrm{~g} \text { hazelnut })\end{array}$ & $\begin{array}{c}\text { Toplam Fenolik Madde } \\
\text { (mg GAE /g ekstre }) \\
\text { Total Phenolics } \\
(\mathrm{mg} \mathrm{GAE} / \mathrm{g} \text { extract })\end{array}$ & $\begin{array}{c}\text { Kondense Tanen } \\
\text { (mg KE/g ekstre) } \\
\text { Condensed Tannins } \\
(\mathrm{mg} \text { CE/g extract })\end{array}$ \\
\hline Fraksiyon I & $0.62 \pm 0.03^{\mathrm{a}}$ & $3.7 \pm 0.1^{\mathrm{b}}$ & $0.9 \pm 0.2^{\mathrm{a}}$ \\
Fraksiyon II & $0.57 \pm 0.04^{\mathrm{a}}$ & $2.4 \pm 0.0^{\mathrm{a}}$ & n.d. \\
Fraksiyon III & $0.79 \pm 0.06^{\mathrm{b}}$ & $11.2 \pm 0.2^{\mathrm{c}}$ & n.d. \\
Fraksiyon IV & $0.55 \pm 0.02^{\mathrm{a}}$ & $10.9 \pm 0.1^{\mathrm{c}}$ & $2.8 \pm 0.2^{\mathrm{b}}$ \\
Fraksiyon V & $1.97 \pm 0.08^{\mathrm{c}}$ & $77.9 \pm 1.2^{\mathrm{d}}$ & $227 \pm 1.3^{\mathrm{c}}$ \\
\hline
\end{tabular}

Sonuçlar ortalama \pm standart sapma olarak verilmiştir $(n=3)$.

Aynı sütunda verilen farklı harfler istatiksel açıdan fark olduğunu göstermektedir $(P<0.05)$.

Kısaltmalar: GAE, Gallik Asit Eşdeğer; KE, Kateşin Eşdeğer.

Data are expressed as means \pm the standard deviation $(n=3)$.

Different letters given within a column, shows significant difference $(P<0.05)$.

Abbreviations: GAE, Gallic Acid Equivalent; CE, Catechin Equivalent.

Daha önce Pelvan Pelitli vd. (2017) tarafindan yapılan çalışmada, düşük molekül ağırlıklı (LMW), ileri saflaştırılmış düşük molekül ağırlıklı (LMWFP) ve yüksek molekül ağırlıklı (HMW) fraksiyonlarına ayrılan findığın verimi sırasıyla $4.40,0.54$ ve $0.65 \mathrm{mg} / 100 \mathrm{~g}$ findik olarak raporlanmıstır. Daha önce yapilan çalışmada düşük molekül ağırlı̆̆ına (LMW) sahip bileşikler tek bir fraksiyon olarak elde edilmişken, bu çalışmada öncekinden farklı olarak, LMW fraksiyonu UV'de verdiği absorbans değerlerine göre ayrılarak toplamda dört ayrı fraksiyon olarak elde edilmiştir.

\section{Toplam fenolik madde miktarları}

Elde edilen fraksiyonların toplam fenolik madde miktarlar1 Çizelge 1'de verilmektedir. En düşük fenolik madde miktarı $2.4 \mathrm{mg}$ GAE/g ekstre ile Fraksiyon II ve en yüksek değer $77.9 \mathrm{mg} \mathrm{GAE/g}$ ekstre ile Fraksiyon V'te tespit edilmiştir. İstatistiksel açıdan fark tespit edilen $(P<0.05)$ numuneler toplam fenolik madde miktarına göre şu şekilde sıralanmaktadır: Fraksiyon $\mathrm{V}>$ Fraksiyon III $>$ Fraksiyon IV $>$ Fraksiyon I $>$ Fraksiyon II.

Literatürde yer alan çalışmalar değerlendirildiğinde; Pelvan Pelitli vd. (2017) tarafindan yapılan çalışmada LMW olarak adlandırılan düşük molekül ağırlığına sahip bileşikler 8 mg GAE/g ekstre ile en düşük değere sahipken HMW olarak adlandırılan yüksek molekül ağırlığına sahip bileşikler 219 mg GAE/g ekstre ile en yüksek değere sahiptirler. Şeker ve organik asitlerin uzaklaştırıldığ1 LMW-FP fraksiyonun toplam fenolik madde miktarı ise 47 mg GAE/g ekstre olarak verilmiştir. Pelvan vd. (2012)'nin farklı findık türlerinde yaptığ1 çalışmada toplam fenolik madde miktarı $178 \mathrm{mg}$ GAE/100 g findik ile $727 \mathrm{mg}$ GAE/100 g findik arasında olduğu belirtilmiştir. Alasalvar vd. (2006)'nin findik zarindan $\% 80$ aseton (v/v) ve $\% 80$ metanol (v/v) kullanarak elde ettiği fraksiyonlardaki toplam fenolik madde miktarı şu şekildedir: Tanen fraksiyonu (Fr.II) için asetonla ekstraksiyonda $697 \mathrm{mg} \mathrm{KE} / \mathrm{g}$ ekstre; metanolle ekstraksiyonda 746 mg KE/g ekstredir. Düşük molekül ağırlıklı fenolik maddeler fraksiyonu (Fr. I) $441 \mathrm{mg} \mathrm{KE} / \mathrm{g}$ ekstre (asetonla ekstraksiyon) ve $442 \mathrm{mg} \mathrm{KE} / \mathrm{g}$ ekstre (metanolle ekstraksyon) ile en düşük değerlere sahip olmuştur. Amarowicz vd. (2005)'nin badem ile yaptıkları çalışmada, fenolik madde ham ekstresi, düşük molekül ağırlıklı fenolik maddeler fraksiyonu (Fr. I) ve tanen fraksiyonunun (Fr.II) toplam fenolik madde miktarları sirasiyla $16.1 \mathrm{mg} \mathrm{KE} / \mathrm{g}$ ekstre, $7.14 \mathrm{mg}$ $\mathrm{KE} / \mathrm{g}$ ekstre ve $80.4 \mathrm{mg} \mathrm{KE} / \mathrm{g}$ ekstre olarak verilmiştir.

\section{Kondense tanen miktarlart}

Elde edilen fraksiyonlarin kondense tanen miktarları Çizelge 1'de verilmektir. Fraksiyon II ve 
Fraksiyon III'te kondense tanen tespit edilmezken Fraksiyon V 227 mg KE/g ekstre ile en yüksek değere sahiptir. Numuneler arasında istatistiksel açıdan fark tespit edilmiştir $(P<0.05)$.

Aseton çözeltilerinin yüksek tanen içeren bitkilerdeki fenolik maddeleri ekstrakte etmede en etkin çözelti olduğu vurgulanırken (MuellerHarvey, 2001; Alasalvar vd., 2006; de la Rosa vd., 2011), metanolün ise daha çok düşük molekül ağırlıklı ve yüksek enzim içeriği olan matriksler için uygun olduğu belirtilmektedir (Arapitsas, 2012). Asetonun diğer çözgenlerden daha etkin olmasının sebebi; kondense tanenlerin yüksek molekül ağırlı̆̆ına sahip olması ve asetonun polaritesinin de bu maddeler için uygun olmasıdır (Alasalvar vd., 2009).

Pelvan Pelitli vd. (2017) tarafindan yapılan çalışmada LMW olarak adlandırılan düşük molekül ağırlığına sahip bileşikler $5 \mathrm{mg} \mathrm{KE} / \mathrm{g}$ ekstre ile en düşük değere sahipken HMW olarak adlandırılan yüksek molekül ağırlığına sahip bileşikler $1001 \mathrm{mg} \mathrm{KE} / \mathrm{g}$ ekstre ile en yüksek değere sahiptir ve tamamının tanenlerden oluştuğu söylenebilir. Şeker ve organik asitlerin uzaklaştırıldığ1 LMW-FP fraksiyonun kondense tanen miktar1 ise $24 \mathrm{mg} \mathrm{KE} / \mathrm{g}$ ekstre olarak verilmiştir. Pelvan vd. (2012)'nin farklı findık türlerinde yaptığ çalışmada kondense tanen miktarları $941 \mathrm{mg} \mathrm{KE} / 100 \mathrm{~g}$ findık ile $1826 \mathrm{mg}$ $\mathrm{KE} / 100 \mathrm{~g}$ findık arasında olduğu belirtilmiştir. Monagas vd. (2009)'nin fistık, findık ve badem ekstrelerini karşılaştırdığı çalışmasında; findığın ham ekstresi ve yüksek molekül ağırlığına sahip ekstresindeki kondense tanen miktarları badem ve fistığınkilerden daha yüksek değerlere sahipken, düşük molekül ağırlıklı ekstresindeki değerler badem ve fistik ile neredeyse benzer değerlerdedir. Kabuklu yemişlerde yapilan kondense tanen çalışmalarında findık en yüksek kondense tanen miktarına sahipken sıralama şu şekilde verilmiştir: findık, badem, kaju, kestane, pikan cevizi ve antep fistığ (Gu vd., 2004; USDA, 2011).

\section{Antioksidan kapasitelerinin belitlenmesi DPPH (2,2-difenil-1-pikrilhidrazil) radikal süpürme kapasitesi}

Antioksidan kapasitenin belirlenmesinde en çok kullanılan yöntemlerden biri DPPH radikal süpürme kapasitesi yöntemidir (Locatelli vd., 2010). Yapılan çalışmada, Fraksiyon II 25.533 $\mathrm{mg} / \mathrm{mL}$ ekstre $\mathrm{IC}_{50}$ değeri ile en düşük antioksidan kapasiteye sahipken Fraksiyon V $0.047 \mathrm{mg} / \mathrm{mL}$ ekstre ile en yüksek antioksidan kapasiteye sahiptir (Şekil 2).
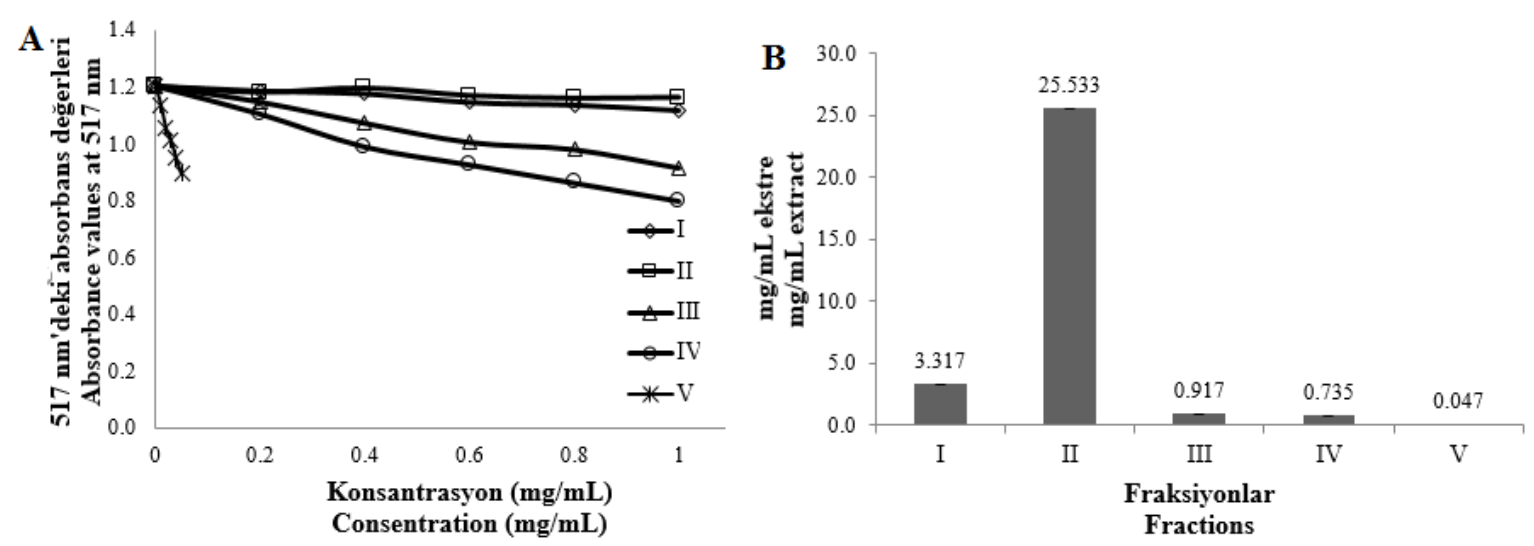

Şekil 2. DPPH yöntemine göre fraksiyonların antioksidan kapasiteleri (A, farklı konsantrasyondaki fraksiyonların 517 nm'deki absorbans değerleri; $\mathrm{B}$, fraksiyonların $\mathrm{IC}_{50}$ değerleri - DPPH radikalini \%50 düşürmek için gerekli $\mathrm{mg}$ ekstre $/ \mathrm{mL})$

Figure 2. Antioxidant capacities of fractions according to DPPH assay (A, Absorbance values of fractions with different concentrations at $517 \mathrm{~nm} ; \mathrm{B}, I C_{50}$ values (the amount of extract required to scavenge the initial DPPH radical by 50\% and expressed as $m g$ of fraction $/ m L$ of sample solution) 
Alasalvar vd. (2006)'nin findık ve findığın yeşil kabuğunda iki farklı çözgen ile yaptığ çalışmada $\% 80$ aseton kullanarak ekstrakte ettiği findığın ham ekstresinde $\mathrm{IC}_{50}$ değerini 0.098 olarak bulmuştur. Alasalvar vd. (2009) tarafindan yapilan başka bir çalışmada findık zarı ham ekstresi ve fraksiyonlarının $\mathrm{EC}_{50}$ değerleri sirasıyla ham ekstre 0.026, Fraksiyon I 0.027 ve Fraksiyon II 0.027 olarak belirtilmiştir. Delgado vd. (2010)'nin yaptığ çalışmada aseton ile elde edilen ekstrelerin en yüksek antioksidan kapasiteye sahip olduğunu belirtmiş ve farklı kabuklu yemişlerin DPPH yöntemi ile analiz edilen antioksidan kapasitelerini şu şekilde sıralamıştır: ceviz $>$ fındık $>$ çam fistığ 1 $>$ fisttk > badem. Monagas vd. (2009)'nin yaptığ1 çalışmada ise fistık, fındık ve bademin zarlarından elde edilen ham ekstre, düşük molekül ağırlıklı fraksiyon ve yüksek molekül ağırlıklı fraksiyonlardan en yüksek antioksidan kapasiteye sahip olanı her bir kabuklu yemiş için yüksek molekül ağırlıklı fraksiyondur ve birbirine yakın değerlere sahiptir. Ham ekstre ve düşük molekül ağırlıklı fraksiyonlar değerlendirildiğinde findık, fistık ve bademe göre daha yüksek antioksidan kapasiteye sahip çıkmıştır.

Pelvan Pelitli vd. (2017) tarafindan yapilan çalışmada, elde edilen fraksiyonların DPPH yöntemine göre analiz edilen antioksidan kapasitelerinin sıralaması şu şekildedir: LMW < LMW-FP < HMW. Bu çalışmada elde edilen sonuçlar daha önce yapilan çalışmalarla uyum göstermektedir.

ABTS (2,2'-azino-bis-(3-ethylbenzthiazoline6-sulfonik asit) radikal süpürme kapasitesi

Antioksidan kapasitenin belirlenmesinde en çok kullanılan yöntemlerden biri de ABTS radikal süpürme kapasitesi yöntemidir. Yapılan çalışmada, Fraksiyon II $0.027 \mathrm{mmol}$ TE/ g ekstre ile en düşük antioksidan kapasiteye sahipken Fraksiyon V 1.442 mmol TE/ g ekstre ile en yüksek antioksidan kapasiteye sahiptir (Şekil 3).
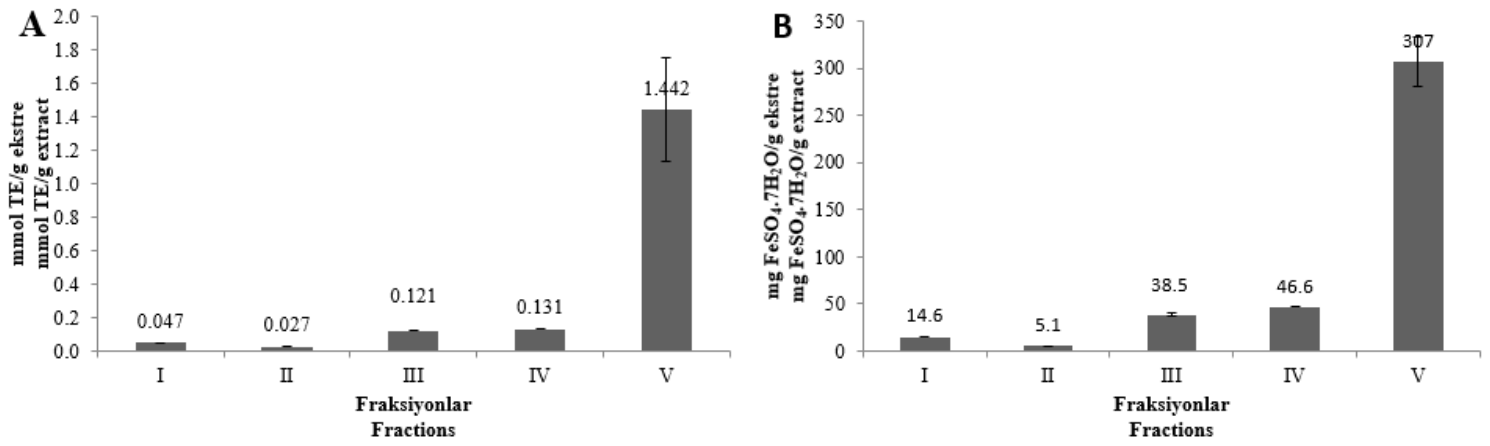

Şekil 3. Fraksiyonların antioksidan kapasiteleri (A, ABTS yöntemine göre; B, FRAP yöntemine göre) Figure 3. Antioxidant capacities of fractions ( $A$, according to ABTS assay; $B$, according to FRAP assay)

Shahidi vd. (2007)'nin \%80 etanol (v/v) ile yaptı̆̆1 çalışmada findığın çekirdek kısmının diğer kısımlarına göre daha düşük antioksidan kapasiteye sahip olduğunu belirtmiştir $(29.0 \mu \mathrm{mol}$ TE/ g ekstre). Monagas vd. (2009)'nin findik, fistık ve bademden elde ettiği fraksiyonların antioksidan kapasitelerini ABTS yöntemi ile değerlendirdiği çalışmasında üründen bağımsız olarak sıralamayı şu şekilde vermiştir: HMW > ham ekstre > LMW.

Pelvan Pelitli vd. (2017) tarafindan yapilan çalışmada, elde edilen fraksiyonların ABTS yöntemine göre analiz edilen antioksidan kapasitelerinin sıralaması şu şekildedir: LMW < LMW-FP < HMW. Bu çalışmada elde edilen sonuçlar daha önce yapılan çalışmalarla ve diğer antioksidan kapasite analiz yöntemleriyle elde edilen sonuçlarla uyum göstermektedir.

FRAP (Demir iyon indirgeyici antioksidan kapasitesi)

Elde edilen fraksiyonların antioksidan kapasiteleri FRAP yöntemi ile de analiz edilmiştir (Şekil 3). Elde edilen sonuçlar diğer antioksidan kapasite 
yöntemleriyle elde edilen sonuçlarla benzer siralamaya sahiptir.

Pelvan Pelitli vd. (2017) tarafindan yapilan çalışmada, elde edilen fraksiyonların FRAP yöntemine göre analiz edilen antioksidan kapasitelerinin sıralaması şu şekildedir: LMW < LMW-FP < HMW. Bu çalışmada elde edilen sonuçlar daha önce yapılan çalışmalarla ve diğer antioksidan kapasite analiz yöntemleriyle elde edilen sonuçlarla uyum göstermektedir. Kamiloglu vd. (2014)'nin kurutulmuş meyve ve kabuklu yemişlerde yaptıkları çalışmada $\% 0.1$ formik asit içeren $\% 75$ metanol çözeltisi ile ekstrakte edilen fındığın antioksidan kapasitesi $201 \mathrm{mg}$ TE/100 g findık olarak raporlanırken bademin antioksidan kapasitesi $20 \mathrm{mg}$ TE/100 g badem ve cevizinki de $1694 \mathrm{mg}$ TE/100 g olarak verilmiştir. Kullanılan farklı çözgenler ve farklı birimler sebebiyle mevcut çalş̧ma ve literatür değerleri arasında direkt karşılaştırma yapılması mümkün değildir.

$\mathrm{Bu}$ çalışmadan elde edilen sonuçlar değerlendirildiğinde, findığın Sephadex LH-20 gel kolon dolgu maddesi kullanilarak polifenolik fraksiyonlarına ayrilmasiyla elde edilen fraksiyonlardan aseton elüenti ile gelen fraksiyon hem antioksidan kapasite açısından yüksek aktiviteye sahiptir hem de kondense tanenler açısından zengindir. Tanenler sağlık üzerine ve g1da kalitesi üzerine olumlu etkileri olan ve yüksek antioksidan kapasiteye sahip maddelerdir. $\mathrm{Bu}$ sebeple findık, yüksek tanen içeriği sebebiyle sağlık açısından önemli bir kaynak olarak değerlendirilebilir. Bu çalışma sonucunda, düşük molekül ağırlı̆̆ına sahip fraksiyonların düşük toplam fenolik madde, kondense tanen miktarları ve antioksidan kapasiteleri sebebiyle ayr1 ayr1 fraksiyonlar olarak elde edilmesine gerek olmadığı, yüksek molekül ağırlıklı fraksiyondan ayrılmasının yeterli olduğu tespit edilmiştir.

\section{TEŞEKKÜR}

Bu çalş̧ma Avrupa Birliği FP7-NutraHEALTH projesi (Grant no: 316012) tarafindan desteklenmiştir. Prof. Dr. Ryszard Amarowicz, Doç. Dr. Cesarettin Alaşalvar ve Dr. Michał
Adam Janiak'a desteklerinden dolay1 teşekkürlerimi sunarım.

\section{KAYNAKLAR}

Alasalvar C., Bolling B.W. (2015). Review of nut phytochemicals, fat-soluble bioactives, antioxidant components and health effects. $\mathrm{BrJ}$ Nutr, 113: 68-78, doi: 10.1017/ S0007114514003729.

Alasalvar C., Karamac' M., Amarowicz R., Shahidi F. (2006). Antioxidant and antiradical activities in extracts of hazelnut kernel (Corylus avellana L.) and hazelnut green leafy cover. J Agric Food Chem, 54: 4826-4832, doi: https://doi.org/10.1021/jf0601259.

Alasalvar C., Karamac', M., Kosińska A., Rybarczyk A., Shahidi F., Amarowicz, R. (2009). Antioxidant activity of hazelnut skin phenolics. $J$ Agric Food Chem, 57: 4645-4650, doi: https://doi.org/10.1021/jf900489d.

Alaşalvar C., Pelvan E. (2009). Günümüzün ve geleceğin gidaları fonksiyonel gidalar. Bilim ve Teknik, 501: 26-29.

Amarowicz R., Estrella I., Hernández T., Dueñas M., Troszyńska, A., Kosińska A., et al. (2009). Antioxidant activity of a red lentil extract and its fractions. Int $J$ Mol Sci, 10: 5513-5527, doi: 10.3390/ijms10125513.

Amarowicz R., Troszyńska A., Shahidi F. (2005). Antioxidant activity of almond seed extract and its fractions. J Food Lipids, 12: 344-358, doi: https://doi.org/10.1111/j.1745-4522.2005.

00029.x.

Arapitsas P. (2012). Hydrolyzable tannin analysis in food. Food Chem, 135: 1708-1717, doi: https://doi.org/10.1016/j.foodchem.2012.05.09 6.

Armada P.L., Rivas S., Gonzalez B., Moure A. (2019). Extraction of phenolic compounds from hazelnut shells by green processes. J Food Eng, 255: 1-8, doi: https://doi.org/10.1016/ j.jfoodeng.2019.03.008.

Barreira J.C.M., Ferreira I.C.F.R., Oliveira M.B.P.P., Pereira J.A. (2008). Antioxidant activities of the extracts from chestnut flower, 
leaf, skins and fruit. Food Chem, 107: 1106-1113, doi: $\quad$ https://doi.org/10.1016/j.foodchem. 2007.09.030.

Benzie I.F.F., Strain J.J. (1999). Ferric reducing/antioxidant power assay: Direct measure of total antioxidant activity of biological fluids and modified version for simultaneous measurement of total antioxidant power and ascorbic acid concentration. Methods En:ymol, 299: 15-27, doi: 10.1016/s0076-6879(99)99005-5.

Contini M, Baccelloni S, Massantini R, Anelli G. (2008). Extraction of natural antioxidants from hazelnuts (Corylus avellana L.) shell and skin wastes by long maceration at room temperature. Food Chem, 110: 659-669, doi: https://doi.org/ 10.1016/j.foodchem.2008.02.060.

de la Rosa L.A., Alvarez-Parrilla E, Shahidi F. (2011). Phenolic compounds and antioxidant activity of kernels and shells of Mexican pecan (Carya illinoinensis). J Agric Food Chem, 59: 152-62, doi: $10.1021 /$ jf1034306.

Delgado T., Malheiro R., Pereira J.A., Ramalhosa, E. (2010). Hazelnut (Corylus avellana L.) kernels as a source of antioxidants and their potential in relation to other nuts. Ind Crops Prod, 32: 621-626, doi: $\quad$ https://doi.org/10.1016/j.indcrop. 2010.07.019.

Ghirardello D., Bertolino M., Belviso S., Belloa B.D., Giordano M., Rolle L., Gerbi V., Antonucci M., Spigolon N., Zeppa G. (2016). Phenolic composition, antioxidant capacity and hexanal content of hazelnuts (Corylus avellana L.) as affected by different storage conditions. Postharvest Biol Tech, 112: 95-104, doi: https://doi.org/10.1016/j.postharvbio.2015.09.0 39.

Gini T.G., Jothi G.J. (2018). Column chromatography and HPLC analysis of phenolic compounds in the fractions of Salvinia molesta Mitchell. Egypt J Basic Appl Sci, 5: 197-203, doi: https://doi.org/10.1016/j.ejbas.2018.05.010.

Gu L, Kelm M.A., Hammerstone J.F., Beecher G., Holden J., Haytowitz D., Gebhardt S., Prior R.L. (2004). Concentrations of proanthocyanidins in common foods and estimations of normal consumption. J Nutr, 134: 613-617, doi: 10.1093/jn/134.3.613.

International Nut \& Dried Fruit Council Foundation (INC), International Nut \& Dried Fruits Statistical Year Book 2018/2019, https://www.nutfruit.org/files/tech/155352137 0_INC_Statistical_Yearbook_2018.pdf. (Erişim tarihi: 01 Temmuz 2019).

Kamiloglu S., Pasli A.A., Ozcelik B., Capanoglu E. (2014). Evaluating the in vitro bioaccessibility of phenolics and antioxidant activity during consumption of dried fruits with nuts. LWT Food Sci Technol, 56: 284-289, doi: https://doi.org/10.1016/j.lwt.2013.11.040.

Karamać M., Kosińska A., Rybarczyk A., Amarowicz R. (2007). Extraction and chromatographic separation of tannin fractions from tannin-rich plant material. PolJ Food Nutr Sci, 57: 471-474.

Koroleva O., Torkova A., Nikolaev I., Khrameeva E., Fedorova T., Tsentalovich M., et al. (2014). Evaluation of the antiradical properties of phenolic acids. Int J Mol Sci, 15: 16351-16380, doi: $10.3390 /$ ijms150916351.

Lainas K., Alasalvar C., Bolling B.W. (2016). Effects of roasting on proanthocyanidin contents of Turkish Tombul hazelnut and its skin. J Funct Foods, 23: 647-653, doi: https://doi.org/ 10.1016/j.jff.2016.03.029.

Locatelli M., Travaglia F., Coïsson J.D., Martelli A., Stévigny C., Arlorio M. (2010). Total antioxidant activity of hazelnut skin (Nocciola Piemonte PGI): Impact of different roasting conditions. Food Chem, 119: 1647-1655, doi: https://doi.org/10.1016/j.foodchem.2009.08.04 8.

Milevskaya V.V., Prasad S., Temerdashev Z.A. (2019). Extraction and chromatographic determination of phenolic compounds from medicinal herbs in the Lamiaceae and Hypericaceae families: A review. Microchem J, 145: 1036-1049, doi: https://doi.org/10.1016/ j.microc.2018.11.041.

Monagas M., Garrido I., Lebron-Aguilar R., Gomez-Cordoves M.C., Rybarczyk A., 
Amarowicz R., et al. (2009). Comparative flavan3-ol profile and antioxidant capacity of roasted peanut, hazelnut, and almond skins. I Agric Food Chem, 57: 10590-10599, doi: 10.1021/jf901391a.

Mueller-Harvey I. (2001). Analysis of hydrolysable tannins. Anim Feed Sci Technol, 91: 320, doi: https://doi.org/10.1016/S03778401(01)00227-9.

Naczk M., Shahidi F. (2004). Extraction and Analysis of Phenolics in Food. J Chromatogr, 1054: 95-111, doi: https://doi.org/10.1016/ j.chroma.2004.08.059.

Napolitano A., Cerulli A., Pizza C., Piacente S. (2018). Multi-class polar lipid profiling in fresh and roasted hazelnut (Corylus avellana cultivar "Tonda di Giffoni") by LCESI/LTQOrbitrap/MS/MSn. Food Chem, 269: 125-135, doi: 10.1016/j.foodchem.2018.06.121.

Pelvan E., Alasalvar C., Uzman S. (2012). Effects of roasting on the antioxidant status and phenolic profiles of commercial Turkish hazelnut varieties (Corylus avellana L). J Agric Food Chem, 60: 12181223, doi: 10.1021/jf204893x.

Pelvan Pelitli E., Janiak M.A., Amarowicz R., Alasalvar C. (2017). Protein precipitating capacity and antioxidant activity of Turkish Tombul hazelnut phenolic extract and its fractions. Food Chem, 218: 584-590, doi: https://doi.org/ 10.1016/j.foodchem.2016.09.070.

Price M.L., Scoyoc S.V., Butler L.G. (1978). A critical evaluation of the vanillin reaction as an assay for tannin in sorghum grain. $J$ Agric Food Chem, 26: 1214-1218, doi: https://doi.org/ 10.1021/jf60219a031.

Shahidi F, Alasalvar C, Liyana-Pathirana C.M. (2007). Antioxidant phytochemicals in hazelnut kernel (Corylus avellana L.) and hazelnut byproducts. J Agric Food Chem, 55: 1212-1220, doi: https://doi.org/10.1021/jf062472o.

Taş N.G., Gökmen V. (2015). Bioactive compounds in different hazelnut varieties and their skins. J Food Comp Anal, 43: 203-208, doi: https://doi.org/10.1016/j.jfca.2015.07.003.

Taş N.G., Yılmaz C., Gökmen V. (2019). Investigation of serotonin, free and proteinbound tryptophan in Turkish hazelnut varieties and effect of roasting on serotonin content. Food Res Int, 120: 865-871, doi: https://doi.org/ 10.1016/j.foodres.2018.11.051.

United States Department of Agriculture (USDA). Database for the Proanthocyanidin Content of Selected Foods, http://www.nal.usda.gov/fnic/foodcomp.

(Erişim tarihi: 15 Aralık 2011).

Yuan B., Lu M., Eskridge K.M., Isom L.D., Hanna M.A. (2018). Extraction, identification, and quantification of antioxidant phenolics from hazelnut (Corylus avellana L.) shells. Food Chem, 244: 7-15, doi: https://doi.org/10.1016/ j.foodchem.2017.09.116 